ройство и водопользование», Саратовский государственный аграрный университет имени Н.И. Вавилова. Россия.

Аржанухина Екатерина Владимировна, канд. c.- $x$. наук, доцент кафедры «Инженерные изыскания, природообустройство и водопользование», Саратовский государственный аграрный университет имени Н.И. Вавилова. Россия.
410056, г. Саратов, ул. Советская, 60. Тел.: (8452) 74-96-51.

Ключевые слова: глобальное потепление; сизенарий; прогноз; агроклиматические ресурсы.

\title{
SCENARIOS OF GLOBAL WARMING AND FORECASTING CHANGES OF AGROCLIMATIC RESOURCES OF THE VOLGA REGION
}

Korsak Victor Vladislavovich, Doctor of Agricultural Sciences, Professor of the chair "Engineering Surveys, Environmental Engineering and Water Management", Saratov State Agrarian University named after N.I. Vavilov. Russia.

Kravchuk Alexey Vladimirovich, Doctor of Technical Sciences, Professor of the chair "Engineering Surveys, Environmental Engineering and Water Management", Saratov State Agrarian University named after N.I. Vavilov. Russia.

Prokopets Roman Viktorovich, Candidate of Technical Sciences, Associate Professor of the chair "Engineering Surveys, Environmental Engineering and Water Management", Saratov State Agrarian University named after N.I. Vavilov. Russia.

Nikishanov Aleksandr Nikolaevich, Candidate of Agricultural Sciences, Associate Professor of the chair "Engineering Surveys, Environmental Engineering and Water Management", Saratov State Agrarian University named after N.I. Vavilov. Russia.
Arjanuhina Ekaterina Vladimirovna, Candidate of Agricultural Sciences, Associate Professor of the chair "Engineering Surveys, Environmental Engineering and Water Management", Saratov State Agrarian University named after N.I. Vavilov. Russia.

Keywords: global warming; scenario; forecasting; agroclimatic resources.

The article studies the issue of forecasting climate changes in the Middle and Lower Volga region. Based on the IPCC global warming scenarios, with the use of regression analysis methods, the forecast sums of precipitation and effective temperatures of the warm season for meteorological stations in the Volga region for the periods up to the middle and the end of the present century are calculated. A reasonable conclusion is drawn that climate change in the region makes it impossible to conduct dry-land farming and the only way to preserve crop production is irrigation.

Удк 631.3:635.21

\section{ТЕОРЕТИЧЕСКОЕ ОБОСНОВАНИЕ ПРОЦЕССОВ ПЕРЕМЕЩЕНИЯ КЛУБНЕЙ КАРТОФЕЛЯ ПО КАЛИБРУЮЩЕЙ ПОВЕРХНОСТИ, ОБРАЗОВАННОЙ ПРАВИЛЬНЫМИ ШЕСТИУГОЛЬНИКАМИ}

\section{МИРКИНА Елена Николаевна, Саратовский государственный аграрный университет имени} Н.И. Вавилова

БЫЧкОВА Наталья Александровна, Профессионально-педагогический колледж ФГБОУ ВО СГТУ имени Гагарина Ю.А.

Изложены теоретические исследования процесса взаимодействия клубней различной формы с шестиугольными отверстиями, был проведен анализ сил, действующих на клубни с поперечными сечениями округлой и эллипсоидной формы.

Введение. Роль картофеля в решении мировой продовольственной проблемы очень велика, поскольку это одна из важнейших продовольственных культур с высокой питательной ценностью и продуктивностью. Как в России, так и в развитых странах одно из ведущих мест занимает возделывание картофеля в сельскохозяйственном производстве.

Картофель занимает особое место среди продуктов питания, составляющих основу продовольственного рынка России, а также оказывает существенное влияние на обеспечение продовольственной безопасности страны.

Государство прочно сохраняет за собой лидирующее положение в мире по уровню среднегодового валового производства картофеля, оставаясь самым крупным производителем (более половины валового производства).

По общим энергетическим запасам картофель занимает пятое место после пшеницы, ку- курузы, риса, ячменя. В его клубнях содержится в среднем 75-80 \% воды и 20-25\% сухих веществ, в том числе от 14 до $22 \%$ крахмала, $2-3 \%$ белка, 0,2-0,3 \% жира, различные витамины, аминокислоты, углеводы и более 20 минеральных элементов, к основным из которых относятся кальций, фосфор, магний, железо.

Картофель служит также отличным кормом для сельскохозяйственных животных. При урожайности 170-200 ц/га картофель дает 5-6 тыс. к. ед. с 1 га. На корм сельскохозяйственных животных используют и отходы, получаемые при переработке картофеля для пищевых целей.

Однако производство этой культуры в России в последние годы практически не расширяется. Во многих регионах страны потери выращенного урожая при уборке, перевозке и хранении составляют более $25 \%$, что создает определенные сложности в снабжении населения страны, 
особенно крупных промышленных центров ценными продуктами питания.

При уборке картофеля, поступающего от комбайнов, содержатся различные примеси: комки почвы, камни, растительные остатки, а также гнилые, поврежденные клубни и нетоварная мелочь. Чтобы довести картофельный ворох до товарной кондиции применяют послеуборочную обработку (в частности очистку и сортирование).

В задачу очистки входит выделение из вороха различных примесей и получение в чистом виде клубней картофеля.

Задача сортирования заключается в разделении клубней картофеля на три фракции: крупную, среднюю и мелкую, обусловленном требованиями, предъявляемыми к семенному материалу, к сырью для перерабатывающей и химической промышленности, а также к продовольственному картофелю.

Процесс сортирования клубней картофеля может осуществляться несколькими способами: сортированием по линейным размерам, массе, объему и плотности [1].

Целью исследования является улучшение качественных и технико-экономических показателей работы картофелесортировальных машин грохотного типа с калибрующими отверстиями правильной шестиугольной формы.

методика исследований. Теоретические исследования процесса калибрования клубней картофеля на фракции выполняли с использованием теоретической механики, прикладной математики и аналитической геометрии. Экспериментальные исследования проводили в соответствии с действующими ГОСТами и частными методиками. Обработку результатов экспериментальных исследований осуществляли методами математической статистики.

В связи с этим работа по совершенствованию технологического процесса калибрования клубней картофеля с высокой точностью и производительностью особенно актуальна.

Режимы работы и параметры грохотных картофелесортировальных машин во многом зависят от размерных характеристик клубней картофеля [2].

Эффективная работа картофелесортировальных машин грохотного типа с максимальной производительностью возможна тогда, когда клубни картофеля непрерывно перемещаются по калибрующей решетной поверхности. Определяющим условием непрерывного перемещения является состояние устойчивого равновесия клубня, запавшего в калибрующее отверстие, которое характеризуется тремя основными уравнениями равновесия плоской системы сил. Как только сумма моментов и сил, стремящихся переместить клубень, превысит сумму моментов и сил, препятствующих перемещению, тогда начнется процесс перемещения вороха по решетной поверхности [3, 4].

Результаты исследований. Перекатывание клубня шаровидной формы при расположении калибрующих отверстий по ходу технологического процесса возможно относительно т. $A$, и $B$ (рис. 1), расположенных на секущей плоскости $N$, перпендикулярной плоскости решета. Так как секущая плоскость $N$ проходит через продольную ось симметрии клубня, мгновенный радиус качения клубня $r_{\kappa}$ будет равен радиусу клубня:

$$
r_{\mathrm{K}}=r_{\text {кл }} .
$$

Ось $O x$ прямоугольной системы координат $x O y$ направлена параллельно поверхности решета и наклонена к горизонту под углом $\beta$.Тогда условие равновесия клубня при возможном перемещении вниз по решету запишется в следующем виде:

$$
\begin{gathered}
\sum P_{o y}=0 \\
P_{j} \sin (\beta+\varepsilon)-G \cos \beta+P_{1 \Sigma} \cos (\gamma-\psi)+P_{2 \Sigma} \cos (\gamma+\psi)=0 \\
\sum P_{o x}=0 \\
P_{j} \cos (\beta+\varepsilon)+G \sin \beta+P_{1 \Sigma} \sin (\gamma-\psi)-P_{2 \Sigma} \sin (\gamma+\psi)=0
\end{gathered}
$$

$$
\sum M_{B}=0 \quad P_{j} B C-G B O O+P_{1 \Sigma} B E=0 .
$$

В систему уравнений (2)-(4) входят углы наклона грохотов $\beta$, шатуна к горизонту $\varepsilon$, угол трения качения клубня по решетной поверхности $\psi$ и угол $\gamma$ между мгновенным радиусом качения и осью $O y$.

Решив систему уравнений, получим:

$\omega^{2} A=g\left[D_{a} \cos (\gamma-\psi) \cdot \sin (\beta-\gamma-\psi)+r_{n} \sin (\gamma-\beta) \sin 2 \gamma\right]$ $/\left[r_{n} \cos (\gamma-\beta-\varepsilon) \sin 2 \gamma-D_{n} \cos (\gamma-\psi) \cos (\beta+\varepsilon-\gamma-\psi)\right]$

Аналогичным образом определено условие равновесия клубней шаровидной формы при возможном их перемещении вверх по поверхности решета:

$$
\begin{aligned}
& \omega^{2} A=g\left[r_{\pi} \sin (\gamma+\beta) \sin 2 \gamma-D_{a} \cos (\gamma+\beta-\psi]\right. \\
& /\left[r_{k \pi} \cos (\gamma+\beta+\varepsilon) \sin 2 \gamma-D_{a} \cos (\gamma+\psi) \cos (\beta+\varepsilon+\gamma-\psi)\right] .
\end{aligned}
$$

Уравнения (5) и (6) равновесия клубней шаровидной формы, находящихся в калибрующих отверстиях, правильной шестиугольной формы. При возможном перемещении вниз и вверх устанавливают взаимосвязь между режимами работы машины - угловая частота колебания решет $\omega$, 
амплитуда $A$, параметрами картофелесортировки - угол наклона калибрующей поверх поверхности $\beta$ и угол наклона линии действия шатуна $\varepsilon$, диаметр окружности вписанной в калибрующее отверстие $D_{\text {вп }}$, и свойствами калибруемых клубней - радиус клубня $\boldsymbol{r}_{\text {кл }}$, угол трения качения клубня по решетной поверхности $\psi$.

Клубни картофеля должны перемещаться по решетам без отрыва от поверхности, так как это исключает дополнительные соударения с элементами решетной поверхности. Безотрывное перемещение клубней по решету возможно при соблюдении неравенства

$$
\omega^{2} A \leq g \cos \beta / \sin (\beta+\varepsilon) .
$$

Форма клубней большинства сортов картофеля существенно отличается от формы шара. Рассмотрим условия равновесия клубней картофеля, имеющих форму эллипсоида вращения.

При перекатывании клубней такой формы по решету они могут занимать два характерных положения: либо перпендикулярно решетной поверхности малой полуосью эллипса в секущей плоскости, либо большой полуосью. Уравнения равновесия для различных случаев положения клубней эллипсоидной формы будут аналогичны уравнениям (5) и (6) для шаровидных клубней. Отличие будет заключаться только в значениях плеч при определении моментов сил.

Сложность определения плеч сил заключается в том, что положение центра мгновенного радиуса качения постоянно изменяется и не совпадает с центром масс клубня эллипсоидной формы (рис. 2).

Использовав параметрическое уравнение эллипса и соотношение размеров поперечного сечения клубня, получим уравнения равновесного состояния клубней при возможном перемещение вниз:

клубень расположен малой полуосью перпендикулярно плоскости решета:

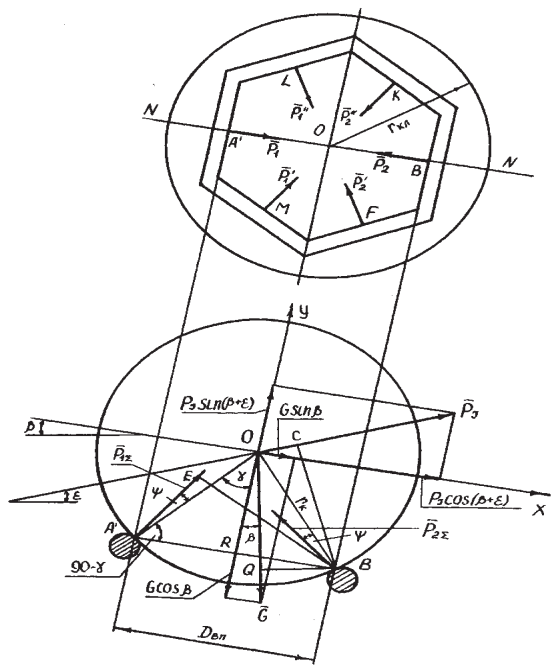

Рис. 1. Схема сил, действующих на клубень шаровидной формы при возможном перемещении вниз по решету
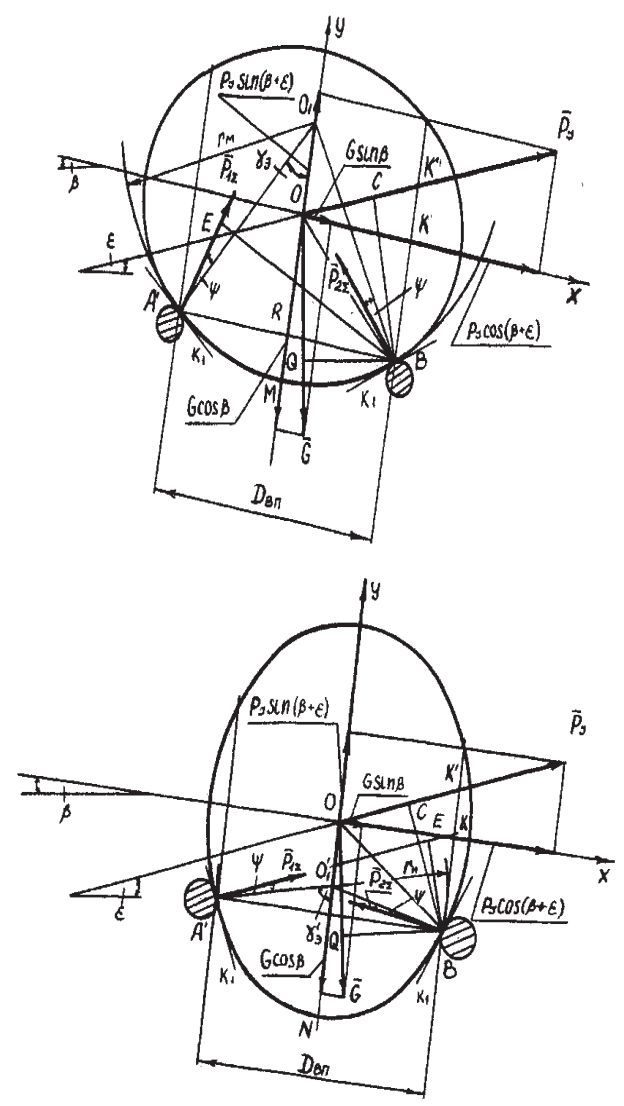

Рис. 2. Схема сил к определению равновесия клубня эллипсоидной формы

$\omega^{2} A=g\left\{0,66 \sqrt{0,43 b^{2}-D_{\mathrm{Bn}}^{2} b^{2}} \cdot \cos \operatorname{arctg}\left(0,29 D_{\mathrm{Bn}} b \sqrt{b^{2}-D_{\mathrm{BI}}^{2}}\right)-\beta\right\rfloor+$ $\left.+D_{\mathrm{B \Pi}} \cos \left(\gamma_{3}-\psi\right) \cdot \sin \left(\beta-\gamma_{3}-\psi\right)\right\} /$

$$
\begin{aligned}
& /\left\{\left|0,44 \quad b \sqrt{0, b^{2}-D_{\text {в п }}^{2}}+0,5 D_{\text {вп }} \sin (\beta+\varepsilon) \cdot\right| \cos (\beta+\varepsilon)-\right. \\
& \left.-D_{\text {в П }} \cos \left(\gamma_{\ni}-\psi\right) \cdot \cos \left(\beta+\varepsilon-\gamma_{3}^{\prime}-\psi\right)\right\}
\end{aligned}
$$

клубень расположен большой полуосью перпендикулярно плоскости решета:

$$
\begin{aligned}
& \omega^{2} A=g\left\{\sqrt{0,25 b^{2}-D_{\text {вп }}^{2}} \cos \operatorname{arctg}\left(0,22 D_{\text {вп }} b \sqrt{0,76 b^{2}-D_{\text {в }}^{2}}\right)-\beta\right\rfloor+ \\
& \left.+D_{\text {вп }} \cos \left(\gamma_{3}^{\prime}-\psi\right) \cdot \sin \left(\beta-\gamma_{3}^{\prime}-\psi\right)\right\} / \\
& /\left\{\left\lfloor 0,57 b \sqrt{0,7 \quad 7 \quad 6 b^{2}-D_{\text {в }}^{2}}+0,5 D_{\text {вп }} \sin (\beta+\varepsilon)\right\rfloor \cos (\beta+\varepsilon)-\right. \\
& \left.D_{\text {вп }} \cos \left(\gamma_{3}^{\prime}-\psi\right) \cdot \cos \left(\beta+\varepsilon-\gamma_{3}^{\prime}-\psi\right)\right\}
\end{aligned}
$$

С помощью полученных уравнений (5), (6) и (7) теоретически определены параметры и режимы работы экспериментальной картофелесортировальной машины (см. таблицу).

Заключение. В ходе теоретического исследования процесса взаимодействия клубней картофеля с колеблющейся решетной поверхностью, образованной правильными шестиугольными отверстиями, расположенными стороной по ходу технологического процесса, были получены:

условия равновесия клубней шаровидной формы, характеризующиеся уравнениями возможного перемещения вниз, безотрывного дви- 
Калибрующие отверстия расположены стороной по ходу технологического процесса

Амплитуда колебаний решета $A$, мм

Частота колебаний решета $\omega, c^{-1}\left(n\right.$, мин $\left.^{-1}\right)$

\begin{tabular}{|c|c|c|c|}
\hline & \multicolumn{3}{|c|}{ Возможные перемещения } \\
\cline { 2 - 4 } & вниз & вверх & отрывом \\
\hline 10 & $50,9(486)$ & $54,8(523)$ & $63,4(606)$ \\
\hline 20 & $36,0(372)$ & $38,7(369)$ & $44,8(428)$ \\
\hline 30 & $29,4(280)$ & $31,6(302)$ & $36,6(350)$ \\
\hline 40 & $25,5(243)$ & $27,4(262)$ & $31,7(303)$ \\
\hline
\end{tabular}

жения от поверхности и возможного перемещения вверх;

ориентировочные значения режимов работы грохотной картофелесортировальной машины при установке калибрующих отверстий правильной шестиугольной формы стороной по ходу технологического процесса.

\section{СПИСОК ЛИТЕРАТУРЫ}

1. Миркина Е.Н., Левченко С.А. Физико-механические свойства клубней картофеля как объект калибрования // Научная жизнь. - 2014. - № 2. - С. 80-81.

2. Миркина Е.Н., Левченко С.А. Влияние угла наклона калибрующей поверхности на точность калибрования. // Научное обозревание. - 2014. - № 1. C. $48-49$.

3. Миркина Е.Н. Обоснование процесса перемещения клубней картофеля по калибрующей поверхнос- ти // Научная жизнь. - 2014. - № 6. - С. 16-17.

4. Миркина Е.Н., Левченко С.А. Режимы перемещения клубней картофеля на калибрующей машине грохотного типа // Научное обозрение. - 2014. № 3. - C. 66.

Миркина Елена Николаевна, канд. техн. наук, доцент кафедры «Инженерные изыскания, природообустройство и водопользование», Саратовский государственный аграрный университет имени Н.И. Вавилова. Россия.

410056, 2. Саратов, ул. Советская, 60.

Тел.: (8452) 74-96-25.

Бычкова Наталья Александровна, преподаватель профессионально-педагогического колледжа ФГБОУ ВО СГТУ имени Гагарина Ю.А. Россия.

410054, г.Саратов, ул. Политехническая, 77.

Тел.: (8452) 99-88-11.

Ключевые слова: клубень; масса клубня; калибрующие шестиугольные отверстия; фракция; решетная поверхность.

\title{
THEORETICAL SUBSTANTIATION OF THE PROCESSES OF MOVEMENT OF POTATO TUBES ON THE CALIBRATION SURFACE, GENERATED BY RIGHT HEXAGONS
}

Mirkina Elena Nikolaevna, Candidate of Technical Sciences, Associate professor of the chair "Engineering Survey, Environmental Management and Water Use”, Saratov State Agrarian University named after N.I. Vavilov. Russia.

Bychkova Natalia Alexandrovna, Teacher, Professional Pedagogical College, Saratov State Technical University named after Gagarin Yu.A. Russia.
Keywords: tuber; weight of tuber; hexagonal sizing holes; fraction; sieve surface.

Theoretical studies of the interaction of tubers of various shapes with hexagonal apertures are presented. An analysis of the forces acting on tubers with cross sections of round and ellipsoidal shape is carried out.

\section{АВТОМАТИЧЕСКАЯ СИСТЕМА ПОЛИВА ДЕКОРАТИВНЫХ PАСТЕНИЙ В ЗАКРЫТОМ ГРУНTЕ НА БАЗЕ ARDUINO}

\author{
ПОРТнов Сергей Алексеевич, Физико-технический лицей № 1 \\ МИХЕЕВА Ольга Валентиновна, Саратовский государственный аграрный университет \\ имени Н.И. Вавилова
}

МИХЕЕВ Иван Александрович, Физико-технический лицей № 1

Рассмотрена автоматическая система полива декоративных растений, которая обеспечивает возможность регулирования не только сроков и норм полива, но и возможность отслеживания нижней и верхней грании, влажности почвы в закрытом грунте, что дает возможность экономить поливную воды в иелом и при необходимости визуализировать процессы на компьютере.

Введение. Во многих европейских странах выращивание декоративных растений в закрытом грунте, т.е. в тепличных условиях, занимает одно из первых мест среди отраслей сельского хозяйства. В Польше, Колумбии, Нидерландах и многих других странах крупные частные хозяйства специализируются на внесезонном выращивании декоративных растений, превращая его в настоящее промышленное производство. Несмотря на строительные проблемы и мате- 